\title{
«Todo enfermo es un canalla...»: Enfermedad y espiritu libre en las cartas de Nietzsche de 1875 a 1879
}

\author{
GIULIANO CAMPIONI
}

La vida de Nietzsche, entre 1875 y 1879, sufre cambios profundos: sale a la luz, a través de subterráneas y largas vicisitudes, la plena conciencia de su identidad filosófica, que halla expresión y forma de vida en la figura del 'espíritu libre'. Esa identidad filosófica había quedado hasta ahora ofuscada y obstaculizada en algunos casos por la profesión filológica (con el peso del deber cotidiano de enseñar) y por la adhesión, cada vez menos convencida, a las ideologías wagnerianas y a sus éxitos. El epistolario de este período, con el aparato crítico que da cuenta ampliamente de los interlocutores y de los testimonios indirectos, ayuda a comprender este complejo y doloroso período de transición, percibible sobre todo en los fragmentos póstumos ${ }^{1}$. Ciertamente, la radicalidad del giro no emerge en las cartas si no es en pocos sitios, y ciertos indicios sólo son comprensibles bajo la luz de las opiniones sucesivas, de lo que seguirá. Por lo demás, ni siquiera a los amigos íntimos, Nietzsche comunica nunca sus sentimientos y opiniones por entero en las cartas, que para él son «imágenes subjeti-

1 Las referencias son a la edición italiana, a cargo de G. Campioni y F. Gerratana, del Epistolario 1875-1879 de Nietzsche, texto crítico establecido por Colli y Montinari, vol. III, Milán Adelphi, 1995. Las «Notizie e note» (pp. 423-636) de este volumen constituyen, en sentido absoluto, el primer aparato crítico sobre las cartas de este período. Para el texto alemán, cf. F. Nietzsche, Briefwechsel, Kritische Gesamtausgabe, ed. G. Colli y M. Montinari, Berlin, W. de Gruyter, Berlin 1975 ss., II Abt., Bd. 5. De ahora en adelante KGB. 
vas de un estado de ánimo». Nietzsche mismo, a menudo, muestra tener conciencia de estas dificultades e imposibilidades. Además, hay que tener en cuenta sus diversas maneras de comunicarse, su uso de la máscara, sus distintas maneras de presentarse a los diversos interlocutores y de cómo quiso que éstos lo entendieran².

Los escritos de Nietzsche son los acontecimientos más importantes de su vida: «escribir quería decir para él vivir» (Montinari). En espe-

2 Para la reconstrucción biográfica son esenciales, junto a las cartas, los testimonios de la tradición indirecta. Una documentación complementaria y magnífica es la recopilación de Sander L. Gilman, Begegnungen mit Nietzsche, Bonn, Bouvier, 19872. Sin sus testimonios personales, no quedaría rastro alguno de algunos interlocutores. Véase por ejemplo la vivaz y brillante descripción del encuentro con el filósofo, como ocasional compañero de viaje, hecho por la baronesa von der Pahlen. Elisabeth von Ungern-Sternberg, entonces joven baronesa von der Pahlen, acompañada por la 'amiga materna' Claudine von Brevern, en su primer viaje a Italia hizo el viaje en tren en compañía de Nietzsche desde Ginebra a Génova. En sus recuerdos (Nietzsche im Spiegelbild seiner Schrift, Leipzig, 1902), la baronesa enumera detalladamente los temas de la fascinante conversación nocturna, mientras la acompañante dormía, con este «Creso del pensamiento que tenía mundos para regalar»: desde los moralistas franceses a la caracterización del libre pensamiento y el espíritu libre. «Llegados a Génova, encontramos alojamiento en los alrededores del puerto, en el mismo hotel, un viejo edificio, y allí transcurrimos algunos días en contacto vivaz con el profesor de Basilea, que todavía no era famoso y era un desconocido fuera de los especialistas y del círculo wagneriano. [...] Hicimos bellas excursiones, entre las que recuerdo más vivamente: un largo paseo nocturno a través de pintorescos pasajes y calles de Génova. La palabra de Nietzsche hizo revivir de manera plástica y vivaz ante los ojos de nuestro espíritu el pasado de Génova. Nos hizo entender el arte renacimental y barroco que daba el sello a 'Génova la Soberbia', la ciudad de los palacios, la antigua rival de Venecia. [...] Nuestra despedida fue por carta porque él sufrió un nuevo ataque de hemicránea» (cf. la carta de Nietzsche del 23 octubre 1876). Nietzsche continuó en barco hasta Livorno. Desde Livorno llegó a Pisa (quizás para encontrar a Rée, que había viajado en tren). La única impresión de esa visita que está atestiguada por las cartas y los escritos, es haber visto aparecer de improviso «en un bosque junto a Pisa, primero dos, después cinco camellos» (El caminante y su sombra, diálogo introductivo). En la finca de $\mathrm{S}$. Rossore junto a Pisa, hasta la segunda guerra mundial, había un criadero de camellos, introducidos a final del 1600, por el Gran Duca Cosimo III de' Medici, e incluso cantados por D’Annunzio en las Laudi (1.III). La baronesa Elisabeth von Ungern-Sternberg encontró de manera fortuita en Pisa a Nietzsche, «que paseaba triste por su calle» y nos ha dejado memoria de ello. El recuerdo del encuentro en la «silenciosa ciudad de las dos torres inclinadas» parece estar muy coloreado por el Chianti bebido por la baronesa, con el estómago vacío, en la estación: el espíritu alegre y la excitación se transmitió, según el testimonio, a Nietzsche (esto suscitará en fin, al regreso a la estación, la agitación y las recriminaciones subsiguientes del fidus Achates Rée a la baronesa, por el influjo 'perjudicial' sobre el filósofo. No faltó la visita al Duomo y al cementerio. Ante el Triunfo de la muerte, «como crítico de la mitología católica se mostró, por un lado, totalmente nuevo, chispeante de argucias y de sarcasmos». 
cial, los libros de este período (Richard Wagner en Bayreuth, Humano, demasiado bumano, Opiniones y sentencias varias y El caminante y su sombra, respecto a las tres primeras Intempestivas que también se movían en la óptica del movimiento wagneriano) pertenecen a la crisis decisiva de la existencia del filósofo. Aparecido a primeros de julio de 1876, Richard Wagner en Bayreuth contribuye a reforzar la imagen pública de Nietzsche como el teórico-activista más brillante y profundo de la causa de Bayreuth. Por eso aumentan en torno suyo los admiradores y los seguidores: el musicólogo Edouard Schuré, el 'poeta de primer rango' Siegfried Lipiner y el grupo de admiradores austríacos, el filósofo schopenhaueriano Emmerich Du Mont, la wagneriana Mathilde Maier, el antisemita Berhard Förster, el músico Hugo von Senger, el médico Otto Eiser, el barón Reinhardt von Seydlitz (por citar sólo algunos interlocutores del espistolario). Humano, demasiado bumano aparece en cambio como apostasía y escándalo y provoca inmediatamente entre los 'amigos' reacciones generales de consternación, estupor y, en el músico y en los más fieles wagnerianos, repulsa y rechazo de todo posible diálogo. En pocos años, Nietzsche parece haber invertido su precedente posición. Las cartas y los apuntes póstumos permiten captar «los dentellones sobre los cuales el nuevo edificio se desarrolla a partir del antiguo» (El caminante y su sombra, § 198). Es una simplificación la dramatización del contraste entre un Wagner que triunfa en Bayreuth y un Nietzsche que se aleja de todo ello desilusionado y dolorido (como sostiene por ejemplo Edouard Schuré); o también su toma de conciencia como revelación repentina, durante el festival, de la lejanía de la realidad de Bayreuth respecto al ideal perseguido (interpretación sugerida a posteriori por el mismo filósofo). De este modo, no se tiene en cuenta que ya el escrito sobre Wagner en Bayreuth, siendo aparentemente apologista, era para Nietzsche un ponerse radicalmente en juego (Carta a Richard y Cósima Wagner de julio 1876); y tampoco cuánto contenía ya ese escrito de crisis de la centralidad del arte y de su fundamento metafísico. En la carta hasta ahora inédita a $\operatorname{Wagner}^{3}$ (n. 537) que acompaña el envío de la Intempestiva sobre Bayreuth, Nietzsche se compara a sí mismo alegóricamente,

3 A R. Wagner, primeros de julio 1876. El manuscrito se halla en el Nationalarchiv der Wagner Stiftung en Bayreuth (IV A 9-10) y ha sido dado a conocer por David Marc Hoffmann en el congreso Nietzsche und die Schweiz (26 agosto, 27 noviembre 1994). En la KGB hay un esbozo precedente que, además de algunas variantes en la puntuación, en los subrayados y en la distribución de los párrafos, contiene una frase omitida en la carta enviada a Wagner. 
por haberse atrevido a publicar el escrito (que pone en cuestión la situación personal), con el «caballero del lago de Constanza», que atraviesa sin darse cuenta, al galope, la superficie helada del lago. Alcanzada la otra orilla e informado de su imposible y loca cabalgata, muere de horror y de espanto por el peligro corrido 4 . En el prefacio de 1886 a $\mathrm{Hu}$ mano, demasiado bumano II, Nietzsche remite «ese miedo póstumo que experimenta cualquiera que haya pasado sin darse cuenta por un peligro monstruoso», no al presunto escrito apologético, sino al sucesivo «horripilante espectáculo» de un Wagner que se doblega, vencido y viejo, ante la cruz 5 . Es una reconstrucción posterior dirigida a resaltar el tema central del conflicto. La carta inédita a Wagner (que sufre versiones tan atormentadas e interiormente contrastantes como la gestación de la cuarta Intempestiva) presenta esta significativa autocensura respecto al esbozo final: «Si tuviera una opinión de Usted mínimamente distinta, no habría publicado este escrito».

El distanciamiento de Nietzsche sólo llega a ser irreversible cuando, en 1878, por parte wagneriana no se quiso aceptar en este terreno (y desde luego no podía ser aceptada) esa reforma radical en la dirección del 'espíritu libre', hacia la que Nietzsche quería empujar el músico. Esa reforma suponía para el arte y el 'genio' la pérdida de su centralidad fundada metafísicamente: las cartas atestiguan estas intenciones. La deshumanización de la naturaleza (el remitir completamente al hombre la fuerza artística atribuida ya al fondo vital) parece implicar al principio una pobreza desolada. La ciencia parece haber desecado las cosas, privándolas de la linfa mágica que el hombre les había infundido. Pero de esa manera le ha dado al hombre un poder más débil pero efectivo sobre la realidad: el hombre se ha convertido en el dios de las máquinas, ha vuelto accesible la naturaleza contentándose con los esquemas y las abstracciones del mecanicismo. La ciencia debe acercarse a las cosas próximas: la metafísica y la religión volaban hacia los dioses y empobrecían a los hombres. Sólo el conocimiento, descuidado hasta ahora, de lo que es «pequeño, débil, humano, ilógico, defectuoso» puede conducir a la sabiduría para la que Nietzsche se siente preparado. Es necesaria la opción del espíritu li-

4 Cf. Gustav Schwab, «Der Reiter und der Bodensee», en Gedichte, Stuttgart, 1828, vol. I, pp. 364-366.

5 KSA 2, p. 372. 
bre por las pequeñas cosas después de la borrachera con los ideales románticos de una riqueza desbordante.

En el telegrama de Venecia (el último mensaje escrito por Nietzsche) que contiene el encargo de «dos camisetas de seda y dos pares de pantalones confeccionados en Basilea, mejor calidad», parece que Wagner casi quisiera cancelar el tiempo y los cambios sucedidos, buscando todavía en el filósofo el devoto famulus de Tribschen. Al marcharse de Basilea hacia Italia, en busca de la salud, Nietzsche tiene en cuenta, en su carta de respuesta, el sentimiento de Wagner, advirtiendo al mismo tiempo la irrecuperable lejanía de Tribschen: el otoño posterior a este verano es más otoño que los anteriores. El gran evento ha dejado tras de sí una estela de la melancolía más negra (a R. Wagner, 27 septiembre 1876).

'Monumento a una crisis', Humano, demasiado bumano es al mismo tiempo la historia de una enfermedad y de una curación. Junto a los dos volúmenes-apéndices que le siguen en marzo y diciembre de 1879, pertenece enteramente a la dura terapia que Nietzsche se ha impuesto a sí mismo. En las introducciones de 1886, Nietzsche eleva esta vicisitud personal a paradigma para aquellos que constituyen la conciencia del alma moderna, «los más espirituales, más valientes», y los únicos que, sintiendo más que los demás la posibilidad de la enfermedad (de la transición), pueden recorrer el camino hacia una «nueva salud». Esta actitud (repasada admirablemente en Ecce homo y en los prefacios autobiográficos de 1886) no es fruto de la conciencia retrospectiva del filósofo que reconstruye el trayecto cumplido felizmente con la reconquista de la propia tarea. Los testimonios de estas tentativas son numerosos en las cartas. En el mismo esbozo de la carta a los Wagner, que debía acompañar Humano, demasiado bumano, Nietzsche escribe: «quizá todavía esté vivo porque he sido capaz de este libro» (676). Los diarios de Cosima ${ }^{6}$ documentan, junto al primer sentimiento de ofensa en Wagner, cuánto dolor costó al músico — hasta la obsesión, que volvía incluso en sueños - el abandono, la 'traición' del joven amigo, y cómo la elección de limpieza racional y de crítica podía parecer, según las palabras de Schuré, un nibilisme écoeurant, primado de un conocimiento histórico que se invertía en escepticismo, y

6 Cosima Wagner, Die Tagebücher, ed. M. Gregor-Dellin y D. Mack, 2 vols., München/ Zürich, Piper, 1976 y 1977. 


\section{fin de toda 'veneración'. Wagner acusará a Nietzsche de 'socratismo' y filisteísmo, en el escrito Público y popularidad’. Aquellos que habían}

7 En una carta del 1 agosto 1878, el editor Schmeitzner informa a Nietzsche de que ha comprado al editor Fritzsch los restos de la primera edición de El nacimiento de la tragedia y toda la segunda edición. También escribe: «Permítame atraer su atención sobre el próximo número (de agosto) de los Bayr. Blätter. El artículo de Wagner «Público y popularidad» [tercera parte] es una réplica a su última obra (Humano e inhumano, como la llama Wagner. El autor no lo cita)» KGB II 6, 955. Wagner, como muestran los Diarios de Cosima, trabaja desde el 3 de julio a la tercera parte de su artículo para los Bayreuther Blätter. Con fecha 21 julio 1879: «R. ha trabajado esta mañana en su artículo larga y gustosamente, me dice que ataca a Nietzsche pero sin que pueda darse cuenta nadie que no esté metido por entero» Tagebücher, II, p. 143. Wagner defiende lo derechos superiores del 'genio', acusando a Nietzsche de aridez 'profesional' y en sustancia de 'filisteísmo cultural': «filólogos y filósofos, sobretodo cuando se topan en terreno de la estética, son animados e incluso obligados por la física a progresar sin limitaciones en la crítica de todo lo humano e inhumano, es decir, parece que de los experimentos de esa ciencia extrajesen una profunda justificación para un conocimiento completamente especial que les consiente, alejándose de las opiniones corrientes y volviendo luego a ellas de manera confusa, girar incesantemente sobre sí mismos, y eso parece que le es asegurado por la parte debida del eterno progreso universal. Más pasan desapercibidos estos saturnales de la ciencia, mayor es la audacia y la crueldad con las que las víctimas más nobles son masacradas y arrastradas sobre el altar de la conocimiento. [...] Los casos más graves se tienen cuando se hecha al mal de manera general toda grandeza, y en particular el tan inoportuno 'genio' como algo perjudicial; antes bien, se rechaza el concepto de genio como fundamentalmente falso. Éste es el resultado del método científico más moderno, que generalmente se define como 'escuela histórica' [...] Quien juzga todas las cosas humanas y divinas, como por último hace con una temeridad extrema quien proviene de la escuela histórica aplicada a la exposición filosófica del mundo, sólo se sirve de las artes archivistas bajo la guía de la química y la física. Ante todo es absolutamente rechazada, y con agrio desprecio, toda hipótesis de que sea necesaria una explicación para los fenómenos del Universo que permanecen quizás impenetrables a un conocimiento de tipo puramente físico. [...] Puesto que ninguna transformación se ha producido sin razón suficiente, resultaría que incluso los fenómenos más sorprendentes, como por ejemplo, más importante de todos, la obra del 'genio', derivan de causas patentes aunque algunas veces demasiado numerosas y aún no explicadas del todo, pero que nos resultará extraordinariamente fácil esclarecerlas cuando la química se haya elevado finalmente a la dignidad de la lógica. Pero entretanto allí donde la cadena de las deducciones lógicas no puede ser considerada como perfectamente adecuada para explicar la obra del genio, se apela a fuerzas naturales más comunes, y sobre todo defectos de voluntad, como la violencia de la voluntad, la energía unilateral y la obstinación, para reconducir lo más posible todo el asunto al campo de la física. Puesto que con el progreso de las ciencias naturales todos los misterios de la existencia tienen que ser necesariamente presentados al conocimiento como misterios en realidad puramente imaginarios, todo depende solo de la conciencia, pero con la exclusión total, parece, del conocimiento intuitivo. Éste, en efecto, podría inducir a extravagancias metafísicas, podría conducir al conocimiento de relaciones que es preciso mantener alejadas del conocimiento científico hasta que la lógica, 


\section{admirado en El nacimiento de la tragedia ante todo la genial transfigu- ración de la empresa wagneriana, retoman ahora los temas de ataque presentes en las Intempestivas, volcándolos contra las nuevas posiciones de Nietzsche. La acusación de socratismo, destructor de la veneración}

guiada por la química hacia la evidencia, no los haya esclarecido. Con ello, hemos aludido, creo yo, a los resultados del nuevo método científico, llamado 'histórico', aunque sólo en superficie (y no puede ser de otro para quien está iniciado a los misterios de la ilustración): gracias a estos resultados el sujeto, puramente cognoscente, que se sienta en una cátedra, queda como el único ser con derecho a la existencia. ¡Una digna aparición como conclusión de la tragedia universal! No es fácil imaginar que podrá experimentar al final este particular que conoce, y quisiéramos que, al final de la carrera, tuviera que repetir las exclamaciones de Fausto al inicio de la tragedia de Goethe! En todo caso, tememos que no muchos podrían compartir con él el gozo del conocimiento, y pensamos que, por aquel gran placer de un particular, pero suponiendo que lo haya, el Estado que se preocupa del interés general derrocharía demasiado dinero. En cuanto a la utilidad general, las cosas irían verdaderamente mal sólo por el hecho de que es difícil ese purísimo sujeto cognoscente como un hombre entre los hombres. Él transcurre su vida delante y detrás de la cátedra, no tiene a su disposición, para el conocimiento de la vida, un espacio más amplio del que deja este cambio de sitio. El aspecto intuitivo de todo lo que piensa le es negado, en la mayor parte de los casos, desde la primera juventud y su contacto con la llamada realidad de la existencia es un despropósito sin sentimiento. Ciertamente nadie le haría tanto caso si no hubiera universidades y cátedras, que nuestro Estado, tan orgulloso de sus doctos, se preocupa de mantener con generosidad. Él, con sus semejantes y otros 'filisteos de la cultura', podrá aparecer como un publico con el que se mezclan de vez en cuando, para despropósitos académicos, pimpollos de príncipes amantes de la lectura. $\mathrm{Al}$ arte, que al Golia del conocimiento le parece cada vez más un rudimento de un estadio precedente de la humanidad [cf. $\S \S 222$ y 223], más o menos como el resto que nos ha quedado de la cola del animal, al arte ya sólo le presta atención si le ofrece perspectivas arqueológicas para justificar afirmaciones históricas escolásticas. Así aprecia él, por ejemplo, la Antígona de Mendelssohn, o unos cuadros de los que pueda informarse leyendo sin estar obligado a verlos. Él produce influjo en el arte sólo en tanto que este influjo debe existir cuando se fundan academias, universidades y cosas parecidas, donde luego él emplea todo su esfuerzo en impedir que emerja una fuerza creativa: de otro modo se podrían provocar fácilmente recaídas en aquel vértigo de la inspiración que es propio de civilizaciones ya superadas. Ni siquiera le pasa por la cabeza dirigirse al pueblo, que por su parte no se ocupa en absoluto de los doctos, pero también es difícil decir por qué camino el pueblo debería llegar por fin a ciertos conocimientos. El pueblo aprende, en efecto, siguiendo caminos completamente opuestos al quien conoce de manera histórico-científica, es decir, en este sentido no aprende absolutamente nada. Aunque no tenga un conocimiento abstracto, el sin pueblo sin embargo conoce: reconoce sus grandes hombres y ama el genio, que aquellos odian; y en fin, algo que a ellos les horroriza, venera lo divino [...] La crítica histórica [...] está sumergida en el judaísmo y se sorprende de que hoy, en una mañana de domingo, suenen todavía las campanas para un hebreo crucificado hace dos mil años [cf. § 113], justo como todo hebreo se sorprende de esto mismo» R. Wagner, Publikum und Popularität, en Gesammelte Schriften und Dichtungen, vol. X, pp. 81-86. 
y de la ilusión (Wabn) necesaria para la vida, es esgrimida, en sus apasionadas cartas a Nietzsche, por la fiel wagneriana Mathilde Maier, que defiende la perspectiva edificante de la música de Wagner incluso para el no-competente. En su respuesta, Nietzsche manifiesta abiertamente, con un sentimiento de liberación, el distanciamiento irreversible respecto a aquel Wagner que pretendía elevar y redimir y que en cambio se había revelado como una enfermedad (734 y 741). Con términos semejantes se expresa Nietzsche en las respuestas a Carl Fuchs, autor de enormes cartas (la que llevará a la reconciliación, después de los malentendidos, es de sesenta y dos páginas en cuarto). Fuchs acepta la fecundidad de las nuevas posiciones de Nietzsche, y su aprecio de Wagner entrará en crisis (cartas 729 y 736) y permanecerá hasta el último momento un interlocutor de Nietzsche (sobre todo en cuestiones musicales). Sobre él, el filósofo realiza una especie de tutela y de dirección cultural como ya había hecho, de manera más ruda y por más tiempo, respecto a Deussen. Éste, una vez que se había emancipado definitivamente, se consolida en aquella vía schopenhaueriana que le había indicado el mismo Nietzsche, pero que ya queda lejos de la que el filósofo está recorriendo en soledad (carta 642).

Las cartas dedicadas a Humano, demasiado bumano y a la 'filosofía del escándalo' se hallan entre las más interesantes para comprender los intentos reformadores de Nietzsche con respecto a Wagner. Los amigos más íntimos también manifiestan una dolorosa perplejidad (Malwida, Marie Baumgartner, incluso Overbeck), aún manteniendo la continuidad de la amistad. En una carta-recensión, Rohde, como muchos otros, vislumbra en la influencia negativa de Rée la razón de este repentino cambio, que considera no obstante como una fase transitoria del pensamiento de Nietzsches.

8 En la carta del 16 junio 1878 (KGB II 6, 895), Rohde reacciona así al envío de Humano, demasiado humano: «Mi sorpresa por este último Nietzschianum ha sido, como puedes imaginarte, grandísima: ¡Así ocurre cuando del calidarium lo echan a uno directamente en un gélido frigidarium! Te digo ahora, con toda sinceridad, amigo mío, que esta sorpresa no ha estado privada de sensaciones de dolor. ¿Cómo se puede uno desvestir de tal manera de la propia alma y tomar la de otro? ¿En lugar de Nietzsche, convertirse de improviso en Rée? Estoy aún estupefacto ante este milagro y no puedo alegrarme de ello, ni tener una opinión precisa, porque no lo he entendido todavía bastante bien». Rohde critica en particular la concepción nietzscheana de la 'irresponsabilidad' (Humano, demasiado bumano, § 107) y la absolutización del egoísmo; hace notar críticamente la influencia, vía Rée, de los sensualistas franceses. «Pero yo no creo desde luego, querido amigo, que tu hayas llegado al final de tu 
Tras desafortunadas vicisitudes académicas y amorosas - y consolaciones musicales con el Tristán-, le llega a Rohde la colocación universitaria, un feliz noviazgo y el matrimonio. Asistimos a su progresivo y casi inconsciente alejamiento de Nietzsche, no sin la amarga sensación de una lenta e inexorable clausura en el horizonte domésti-

vida, tu evolución describe una curva, y quizá un día [...] volverá a su dirección originaria». Rohde alaba por lo demás la 'indecible' riqueza de la obra, y en particular las consideraciones de Nietzsche sobre los griegos. El juicio de Rohde sobre Humano, demasiado bumano expresado en la carta a Overbeck del 16 junio 1878 (Overbeck-Rohde Briefwechsel, ed. A. Patzer, Berlin, Gruyter, 1990, p. 25) hace entender cómo también en Overbeck estaban presentes reservas y perplejidades: «También para mí, naturalmente, el último libro de Nietzsche, con ese infeliz título, ha sido en las últimas semanas objeto continuo de estupor y en gran parte de doloroso estupor». Los juicios decididamente críticos y sin indulgencia de Richard Wagner se hallan en los diarios de Cosima. 24 Junio: «R. lee algo en el nuevo libro de Nietzsche y se sorprende de la pretenciosa banalidad. "Entiendo que le parezca más agradable la compañía de Rée que la mía". Y cuando hago notar que después de este libro los precedentes libros de Nietzsche sólo eran reflejos, que no provenían de su interioridad, él dice: «Ahora son Réeflejos» [Réeklekse = manchas de Rée $]$. El juicio de Cosima Wagner sobre el libro está atestiguado por su carta a Marie von Schleinitz: «No he leído el libro de Nietzsche. Me ha bastado hojearlo y leer algunas frases pregnantes para ponerlo ad acta. En el autor se ha cumplido un proceso que desde hace tiempo veía avanzar y contra el cual he combatido con mis pocas fuerzas. ¡Muchas cosas han contribuido al nacimiento de este libro! Se ha añadido también, al final, Israel, en la figura de un doct. Rée muy escurridizo, muy frío, aparentemente cogido y sometido por Nietzsche, en realidad en cambio es él quien lo domina con el engaño; a pequeña escala, la relación entre judaísmo y germanismo [...] Malwida niega decididamente el influjo negativo del doct. Rée, que a usted le gusta tanto... Me ruega también que no abandone a Nietzsche, pero por cada frase que he leído tengo un comentario, y se que aquí ha vencido el mal. Es muy triste la impresión que suscita en nuestros amigos. El joven doct. Schemann se lamenta del libro, pero lo considera el más bello que ha sido escrito nunca. Malwida piensa que contiene reflexiones estupendas, y el fielísimo Wolzogen que ahora ya no podría leer los primeros escritos. Yo no encuentro en él nada de todo ello, sino sólo una tristísima experiencia, que ha durado algunos años. El mismo Wagner sostiene acerca de Nietzsche que de este bulbo tendría que haber nacido una flor. El bulbo se quedó atrás, verdaderamente algo repugnante» KGW IV 4, pp. 46-47. El wagneriano Ludwig Schemann (1852-1938), filósofo y escritor, dedicará gran parte de su actividad a dar a conocer a Gobineau en Alemania (fue traductor, editor de textos, biógrafo y fundador de la Gobineau Vereinigung). Había conocido a Nietzsche en Bayreuth. De este encuentro ha dejado testimonio (ahora en S. Gilman, op. cit., p. 289). Véase también la carta llena de devoción y gratitud por los alientos recibidos, dirigida a Nietzsche el 22 febrero 1878 desde Göttingen, donde Schemann trabajaba de bibliotecario (KGB II 6, 805). También R. v. Seydlitz en la carta del 19 junio 1878, trata críticamente sobre Humano, demasiado bumano: «El ideal del que usted hablaba no lo he encontrado; todo es incluso demasiado réeal $[\ldots .$.$] ¿cuándo escribirá de nuevo un libro$ nietzscheano?» KGB II 6, 900. 
co y profesional. Rohde parece hallar en Wagner la posibilidad de una compensación y transfiguración ideal de la realidad cotidiana. Pero frente a Nietzsche que lo define como poseído completamente por el 'demonio filológico', como un 'archifilólogo', Rohde responde caracterizando así sus propios sentimientos ante el trabajo filológico: « ¡Si fuese al menos un verdadero erudito! Un Wagner [el famulus de Fausto] todo entero! En cambio lo soy sólo a medias, y a la vez sólo un veinteavo de Fausto; y a partir de estas dos naturalezas son creados homúnculos muy extravagantes, ante los cuales incluso los mejores amigos sacuden la cabeza. Espero no obstante que mi 'alma concupiscible' se duerma un día, y estoy seguro que entonces incluso fuerzas mejores que las wagnerianas, sin estorbo, se liberarán y se pondrán en acción. Por el momento, no voy a dejar nunca demasiado libre a mi 'voluntad', para poderme dedicar completamente a problemas realmente serios e importantes, problemas a los que nos debe conducir por lo demás una participación muy decidida de la 'voluntad', que en mí está dirigida hacia una dirección muy diferente, y en otras partes es sacudida de aquí para allá. Actualmente tomo la filología como una persona inquieta y nerviosa toma un polvito efervescente. Amigo mío, ¡qué nostalgia de Bayreuth, el único lugar en el mundo donde yo, mis dolores y juntamente la filología y todo elemento wagneriano y este fatal aire hinchado académico se liberan completamente y pueden naufragar en un mar de placer!»9. La amistad de Nietzsche y Rohde se revela en comunicaciones - tras largos intervalos- muy intensas, llenas de añoranzas, como en la carta que llega a Nietzsche en diciembre de 1879, en el culmen de sus sufrimientos y soledades (carta 920).

El otro gran amigo de juventud, Carl Gersdorff, interrumpe bruscamente a finales de 1877 — y por un largo período de tiempo- las relaciones con Nietzsche, ya que no toleraba la intromisión del amigo y de Malwida en su tempestuosa y reñida vicisitud de noviazgo con la condesa italiana Nerina Finocchietti.

El epistolario revela el papel, tan infravalorado por muchos estudiosos de Nietzsche, cuanto sobrevalorado por los wagnerianos, del 'incomparable' Rée. Entre los dos amigos existía entonces un auténtico paralelismo (incluso, durante un tiempo, en el sufrimiento y en la enfermedad), una confrontación recíproca sobre un terreno de intereses comunes, que en Nietzsche tenían lejanas raíces. Rée es consciente 
de sus deudas culturales con respecto a Nietzsche, y también de la mayor amplitud del territorio explorado por el amigo, territorio al cual él no tiene acceso. Para Nietzsche, Rée representa la primera relación personal y fecunda con un filósofo de su época, de grandes lecturas y actualizado.

Distinto es el caso de Heinrich Köselitz (Peter Gast). Músico de poco talento, amigo del editor Schmeitzner, entra en escena en estas cartas y está destinado a tener en los años sucesivos un papel cada vez más importante (no siempre positivo para el 'éxito' de Nietzsche) como discípulo fiel y el interlocutor más asiduo. Gast es un 'nietzscheano': si en nombre de la metafísica del arte y suscitando escándalo en Basilea, defiende a Wagner en la torpe polémica contra Bagge, después sigue a Nietzsche en su giro, lo 'interpreta', le ayuda, lo cura, lo protege. Al sentirse su discípulo (nueve años más joven), le hablará siempre de usted al filósofo: transcribe los manuscritos, interviene y discute sobre aspectos particulares de las teorías del filósofo, lo asimila: Nietzsche lo define como «colmado de mis pensamientos» (894). Es suyo el informe editorial de Schmetzner con los juicios sobre Nietzsche.

A Nietzsche le vuelven a menudo las reflexiones sobre la amistad: los amigos que no han cambiado su manera de sentir y ver el mundo, ante una fuerte e imprevista transformación, son como 'fantasmas de nuestro pasado': hablan como nosotros mismos hablábamos y nos resultan extraños. Escribe a Rohde: «dado el caso que estuviese en peligro la amistad... esto significaría que honraremos la verdad y diremos: "hasta ahora hemos amado en el otro un fantasma" ${ }^{10}$. Se abre ante Nietzsche el difícil trayecto por un camino que se hará cada vez más solitario.

Resulta curioso el papel desempeñado por el editor Schmeitzner, tal cual aparece en estas cartas: activo en la fundación de los Bayreuther Blätter, interesado en una política cultural coherente y ambiciosa, sin ser todavía activista antisemita, cree en Nietzsche y también lo aprecia en el plano humano. En una previsión errada de incremento en las ventas, no evita momentos de escándalo y clamoreo (no huía de la 'música a la turca', carta del 23 noviembre 1878) hasta que la virulencia de la reacción de Wagner no corre el riesgo de aplastarlo. Sus elecciones cada vez más decididas por una activa política cultural antisemita provocarán la ruptura con Nietzsche.

Además de los personajes a los que se ha hecho brevemente alusión, en torno a Nietzsche giran algunas figuras femeninas sobre las 
que es conveniente detenerse. Mientras la madre Franziska, ligada al hijo enfermo por un afecto posesivo, permanece como depositaria de la estrecha 'virtud de Naumburg', Elisabeth alcanza al hermano en Basilea y con él comparte el apartamento en el $n^{\circ} 48$ de Spalenthorweg. Pero la convivencia, iniciada en el verano de 1875 , se interrumpe a finales de junio de 1878 por motivos no explicitados. Elisabeth interviene con decisión en los vagos intentos del hermano por encontrar esposa, tras las imprevista y torpe proposición de matrimonio a Mathilde Trampedach, sucedida en abril de 1876. La inocente Louise Ott, conocida el mismo año en Bayreuth, tendrá con Nietzsche una relación epistolar sublimada y sosegada. Pero sobre todas destaca la personalidad de Malwida von Meysenburg. La crisis de fin de año de 1875 ve empeoradas las condiciones de salud y paralelamente el presentimiento, pero quizá también la certeza, del distanciamiento respecto a Wagner. En la primavera de 1876 , tras la estancia en las cercanías del castillo de Chillon, Nietzsche parece haber sido restituido a sus 'ideales'. En sus cartas desde Ginebra, se pronuncia decididamente contra la debilidad y el escepticismo. Según las declaraciones del mismo Nietzsche, la 'idealista' Malwida, con su libro recién salido, tiene un papel decisivo en la recuperación temporánea y particular del filósofo a los ideales de Bayreuth: ideales que ve en la necesidad de ser reformados. El libro es leído y aconsejado a los amigos: actúa profundamente como estímulo hacia la autodeterminación y la consecuente 'curación' (cartas 519 y 520). El tema central del permanecer 'fieles a sí mismos' se refuerza: es el inicio del tirocinio del 'espíritu libre', que será completado luego en la relación con Rée. La lectura de Malwida lo fortifica en la dirección de un ideal individual que hay que perseguir: «soy más libre» (escribe Nietzsche en la carta) y también Malwida ha querido recorrer «el sendero solitario de aquellos que persiguen la verdad».

También la carta de cumpleaños pretende imponer a Wagner el ideal que Nietzsche mismo profesaba en estos años: no la clausura en el mito y en la metafísica del genio, sino la pluralidad y la confrontación que potencian el individuo: Wagner debería ayudar, en esta óptica, a descubrir y a potenciarse a sí mismos (empuja hacia arriba: excelsior ${ }^{11}$ ). La acción de Wagner es la de «hacerme más libre y mejor». En Malwida encontraba estímulos nuevos hacia el deber de la autodeterminación: la obligada renuncia al arte por motivos de salud empu- 
ja a la mujer a la decisión de «cooperar con el pensamiento y con la acción por el progreso del género humano» (un ideal humano-genérico todavía presente en Humano, demasiado bumano). Escribe Malwida: «la Religión, salida de la región metafísica, debe transformarse en ejercicio de caridad y conducir a la igualdad y a la fraternidad entre los hombres». Es un aspecto del sentimiento de caritas que Nietzsche valoriza en Malwida. Ella despliega esta actitud respecto al infeliz Brenner (enfermo física y anímicamente), 'joven viejo' que en su breve existencia atraviesa de manera rápida e intensa este epistolario.

Los años de 1875 a 1879 están profundamente marcados por la enfermedad. Ya en el 1878, por parte de Wagner y de su círculo, el distanciamiento de Nietzsche sólo se entiende con respecto a la enfermedad, al 'caso' Nietzsche entendido como caso clínico, psicológico, patológico (cf. por ejemplo la carta de Wagner a Overbeck, 24 mayo 1878). El juicio exorcista seguirá siendo una constante de la literatura wagneriana: hasta las afirmaciones presentes en las cartas de Cosima convertida ya en sacerdotesa, en clave empresarial, del templo de Bayreuth. A la muerte del filósofo, Cosima recorre sin piedad la historia, explicando su 'traición' hacia el precedente objeto de amor (de quien habría obtenido su «auténtica relevancia») en los términos tranquilizadores de la patología: «un proceso de disolución» física y mental, que sin embargo no puede explicar la «maldad» (carta a Malwida von Meysenburg, 8 octubre 1900)12.

El tema de la enfermedad está presente, casi exorcizado, en la carta del 2 de enero de 1875, cuando Nietzsche afirma que su libre actividad de escritor le ha sido robada a sí mismo, respecto a la obligación cotidiana de la enseñanza, en los períodos de enfermedad. Pero ahora escribe: «mis condiciones físicas son óptimas, no hay enfermedades a la vista y los baños fríos cotidianos dejan mi futuro como escritor casi sin esperanzas...». En otros momentos de las primeras cartas, Nietzsche habla de su firme decisión de «querer hacerse viejo» para realizar la propia tarea, y los primeros avisos de enfermedad que le obligan a renunciar a los ensayos de Bayreuth (en el verano de 1875) para curar sus molestias en el estómago, son aceptados serenamente: «¡la desesperación en todas partes! ¡y no en mí! ¡Y sin embargo no estoy en Bayreuth! (p. 87). La enfermedad es combatida para poder vivir plenamente «los años sagrados de Bayreuth» y el acontecimiento del año siguiente. 
También la carta para el cumpleaños de Wagner, que precede por poco tiempo la decisión de curarse en Steinbad, hace referencia en su final a la enfermedad: a la generosidad del 'genio', en la plenitud de fuerza y salud, se contraponen la miseria y el egoísmo que se incuban en la enfermedad («todo enfermo es un canalla...»)(449).

Bien pronto, con un crescendo impresionante, la enfermedad toma posesión dramáticamente de la vida de Nietzsche, hasta transformar sus cartas en un diario, a veces en un auténtico registro estenográfico, de los sufrimientos cotidianos, con pocos alivios momentáneos. En las últimas cartas de este volumen, Nietzsche resume lacónicamente el período transcurrido: condiciones terribles, inquietantes, espantosas, «118 duras jornadas de ataques: una buena estadística». En Ecce homo, Nietzsche vuelve a recorrer este período en el que, in media vita, convertido en 'sombra' y sin esperanzas, se siente «envuelto por la muerte». El sentido de la decadencia, del estar «clavado cerca de la muerte», es conectado obsesivamente con el sentirse predestinado a repetir el fin del padre (lo comunica incluso por carta: a Marie Baumgartner, 14 julio 1875, y a Gersdorff, 18 enero 1876). En el 1879 , después de abandonar definitivamente la universidad, incluso se difunde el rumor de su muerte.

También las cartas reflejan este estado de mínimo vital: prevalece la obligada brevedad de la comunicación (sobretodo en las postales), Nietzsche se excusa por la imposibilidad de escribir cartas, y los amigos escriben por él al dictado o por su cuenta, como Rée desde Sorrento.

Con la agudización de los dolores se acompaña un sutil proceso de autocomprensión. A veces ve la causa en la mole de un trabajo autodestructor ( «iPorqué se acepta una cátedra a los venticuatro años!»). A veces en cambio, justo el haberse alejado del 'orden' y de la regularidad del estudioso, lo ve como algo morboso: la música de Wagner, la metafísica, el 'romanticismo' («la cercanía de Wagner no es cosa para enfermos» p. 224). Y así se alternan las actitudes. Por una parte, Nietzsche programa estudios filológicos de largo alcance, no quiere renunciar a la enseñanza y a su 'oficio' de 'sano' estudioso (630); por otro lado, declara que de todos modos academia derelinquenda est. En Ecce homo ya no hay contradicción entre las dos vías: una se remite necesariamente a la otra. La mecanicidad y la miseria de la 'profesión' necesitan como narcótico, para «anestesiar un sentimiento de hambre 
y desolación», un arte que idealice, transfigure y aleje de la realidad. Nietzsche caracterizará, en la introducción a la segunda edición de $L a$ gaya ciencia, su experiencia de estos años como una «tiranía del dolor, vencida aún por la tiranía del orgullo que rechazaba las conclusiones del dolor». Está la voluntad decidida de no querer dejar hablar la enfermedad incluso allí donde se presenta bajo la máscara de la inactualidad y de la voluntad de futuro, con la mirada agudizada para todos los indicios de la enfermedad. La elección de la pequeña felicidad, del jardín de Epicuro, tranquilizador de almas, el Zwinger con el huerto para cultivar, la torre, incluso el convento para 'espíritus libres', se demostrarán como expedientes provisionales del enfermo que intenta resistir. El optimismo de Epicuro está conectado con el sufrimiento, él fue un sufriente. Así también el lema de Nietzsche «alegrarse uno del otro», la elección antischopenhaueriana del Mit-Freude, el énfasis sobre la amistad (mientras muchos amigos se van): todo ello se descubre como fruto de la buena voluntad de no hacer hablar al resentimiento, de no dejar translucir en el enfermo al 'canalla' (como escribía Nietzsche a Wagner). Al contrario, Nietzsche manifestará su gratitud a la enfermedad, por haberlo desligado lentamente, sin traumas, de los vínculos habituales y por haberlo conducido al abandono de la profesión, transformándolo en un fugitivus errans.

Una palabra vuelve una y otra vez en las cartas de Nietzsche: 'paciencia'13. En las más terribles condiciones «se necesita paciencia y tener paciencia», dolor y enfermedad le han enseñado a «tejer el hilo de la paciencia». Y escribe en Ecce homo: «iPero pensar es precisamente esto!...». La enfermedad es un tema filosófico central para Nietzsche: también estas cartas confirman, con sus frecuentes reflexiones, la complejidad del tema y la veracidad de las páginas autobiográficas sucesivas. 